\title{
Synadenium umbellatum: citotoxicidade e danos ao DNA de células da medula óssea de camundongos
}

\author{
Marize Campos Valadares ${ }^{1 *}$, Núbia Cristiana de Castro ${ }^{1}$, Luiz Carlos da Cunha ${ }^{2}$
}

'Laboratório de Farmacologia e Toxicologia Celular, Faculdade de Farmácia, Universidade Federal de Goiás, 2Núcleo de Estudos e Pesquisas Tóxico-Farmacológicos, NEPET-UFG, Faculdade de Farmácia, Universidade Federal de Goiás

${ }^{*}$ Correspondencia:

M. C. Valadares

Faculdade de Farmácia

Universidade Federal de Goiás

Praça Universitária, esquina com a

primeira avenida $\mathrm{s} / \mathrm{n}$, Setor

Universitário

74605. 220, Goiânia, GO, Brasil

E-mail: marizecv@farmacia.ufg.br
No presente estudo investigamos o potencial citotóxico e mutagênico, in vitro $e$ in vivo, respectivamente, do extrato etanólico de Synadenium umbellatum (EESU) sobre células da medula óssea de camundongos. A citotoxicidade in vitro foi avaliada por meio da exposição de células da medula óssea de animais normais a diferentes concentrações $(40-0,312 \mathrm{mg} / \mathrm{mL})$ do EESU, por 12, 24 ou 48 h, utilizando os testes de redução do MTT e o de exclusão do azul de tripano. $O$ ensaio de micronúcleo foi realizado para investigar potenciais efeitos mutagênicos do EESU (10, 25 ou 50 $\mathrm{mg} / \mathrm{kg} /$ dia) sobre a medula óssea de camundongos. Os animais foram expostos a uma única dose, por via oral, e 24 h após à exposição, sacrificados para realização do estudo ( $n=5 / g r u p o)$. Os resultados obtidos demonstraram que o EESU possui potencial efeito citotóxico e mutagênico, de forma dose-dependente, sobre as células da medula óssea de camundongos, in vitro $e$ in vivo, respectivamente. Maiores estudos são necessários para expandir o conhecimento acerca do potencial toxicológico/farmacológico do EESU.

\section{INTRODUÇÃO}

A espécie botânica Synadenium umbellatum pertence à ordem Geraniales e à família Euphorbiaceae. Esta família compreende cerca de 290 gêneros e aproximadamente 7.500 espécies. Os maiores centros de dispersão encontram-se nos trópicos, continente americano e africano (Ortêncio, 1997). São plantas de hábito variado, existindo ervas, subarbustos e árvores, com folhas alternadas inteiras ou partidas, em geral com estípulas, latescentes ou não (Joly, 1977). As euforbiáceas produzem albuminóides tó- xicos, sendo a ricina o mais conhecido (Quer, 1962).

O Synadenium umbellatum é conhecido popularmente como "cola-nota", "avelós", "milagrosa", "cancerola", sendo o látex empiricamente recomendado para o tratamento do câncer como se segue: "Colocar 18 gotas do látex em 1 L de água e conservar na geladeira. Tomar pela manhã, à tarde e à noite um cálice de licor ou uma xicarazinha de café ou, substituir a água pela solução bebendo várias vezes ao dia. Usar sempre para cura e prevenção" (Ortêncio, 1997).

Dentro da família Euphorbiaceae diversos espécies 
possuem elevada toxicidade. Em levantamento no Estado de Goiás, o Centro de Informações Toxicológicas (CITGO) constatou que, dentre as 18 espécies botânicas relatadas como responsáveis por ocorrências de intoxicações por plantas no Estado, cinco delas (28\%) pertenciam à família Euphorbiaceae, sendo elas a Euphorbia milii (coroa de cristo, cristo gigante); Euphorbia tirucalli (graveto do cão, figueira do diabo, dedo do diabo); Jatropha curcas (pinhão de purga, pinhão paraguaio, pinhão bravo, purgão de cavalo); Ricinus communis (carrapateira, rícino, mamoeira, palma de cristo, carrapato); Manihot utilissima (mandioca amarga, mandioca branca, mandioca, anaçunipeba) (D’ávila, Cunha, 2001; Rezende, Palhaes, Cunha, 2006; CIT-GO, comunicação pessoal).

Revisando a literatura, não se encontrou relato acerca de estudos farmacognósticos, farmacológicos e toxicológicos sobre a Synadenium umbellatum. Entretanto, foram encontrados estudos com alguns espécies do gênero acerca da atividade antiinflamatória (Jäger, Hutchings, Van Staden, 1996) e atividade antitumoral, a exemplo da Euphorbia tirucalli (Kupchan et al., 1976; Schroder et al., 1980; Hubert De-Thé, 1982; Abo et al., 1988; Valadares et al., 2005). Paradoxalmente, diversos artigos publicados sobre as atividades tóxicas de representantes desta família reportam os efeitos carcinogênicos e/ ou co-carcinogênicos de fitocompostos bioativos. Estes trabalhos atribuem ao látex da Euphorbia tirucalli L. africana efeito carcinogênico e/ou modulador de carcinogênese (Furstenberber, Hecker, 1986; Van Den Bosch et al., 1993; Imai et al., 1994; Macneil et al., 2003).

Dentre os métodos para investigação de toxicidade genética in vivo, o teste de micronúcleo em células da medula óssea de camundongos tem sido amplamente empregado e aceito pelas agências reguladoras e comunidade científica (Mateuca et al., 2006). Este teste detecta alterações genômicas ou/e dano ao aparato mitótico, sendo os micronúcleos indicativos de perdas irreversíveis de DNA. Embora a toxicidade genética não seja medida de carcinogenicidade, esta é freqüentemente associada ao aparecimento do câncer, visto que, existe uma correlação positiva entre o aumento da freqüência de micronúcleos e o aparecimento de tumores em roedores e no homem (Azevedo et al., 2003; Rezende, Palhaes, Cunha, 2006).

A medula óssea é formada por diferentes populações celulares incluindo células tronco hematopoiéticas, que dão origem às diversas células do sistema imuno-hematopoiético. Devido à grande capacidade proliferativa do tecido hematopoiético, as células da medula óssea são alvos freqüentes da ação tóxica de xenobióticos (Yamaguchi et al., 1994). Desta forma, a avaliação da integridade das células hematopoiéticas é um parâmetro importante para o entendimento dos mecanismos envolvidos na alteração da produção de células sanguíneas e como estas mudanças coletivamente irão impactar o sistema imuno-hematopoiético (Deldar et al., 1988; Parent-Massin, Thouvenot, 1993; Yamaguchi et al., 1994; Parchment, 1998; Gribaldo et al., 2000; Negro, Bonato, Gribaldo, 2001; Pessina et al., 2001; Gribaldo, 2002; Pessina et al., 2003; Diodovich et al., 2004).

No presente estudo, investigamos os efeitos citotóxicos e mutagênicos do extrato etanólico do Synadenium umbellatum (EESU) sobre células da medula óssea de camundongos in vitro e in vivo, respectivamente.

\section{MATERIAL E MÉTODOS}

\section{Synadenium umbellatum}

O material botânico (folhas) do Synadenium umbellatum foi coletado do espécime cultivado no horto de plantas medicinais da Faculdade de Farmácia da Universidade Federal de Goiás. A exsicata do material, contendo caule, folhas, flores e frutos, foi depositada no Herbário do Instituto de Ciências Biológicas desta Universidade, para a identificação botânica (UFG-27160).

\section{Extrato etanólico do Synadenium umbellatum}

Aproximadamente $5 \mathrm{~kg}$ de folhas da planta foram coletados e colocados para secagem por período de $48 \mathrm{~h}$ em estufa com circulação de ar a $40{ }^{\circ} \mathrm{C}$. Depois da secagem total, as folhas quebradiças foram trituradas até a obtenção de pó fino. Foram realizadas três etapas de extração (a cada $100 \mathrm{~g}$ de massa das folhas trituradas adicionaram-se $500 \mathrm{~mL}$ de álcool etílico 95\%). A mistura foi agitada mecanicamente por $5 \mathrm{~h}$, sendo depois filtrada em papel de filtro (Whatman ${ }^{\circledR} n^{\circ} 1$ ). Os três filtrados foram reunidos, homogeneizados e levados para a concentração em rotaevaporador obtendo-se rendimento final do extrato alcoólico de aproximadamente $50 \mathrm{~g}$ (Schenkel, Gosmann, Petrovick, 1999).

\section{Animais}

Para a realização dos experimentos foram utilizados camundongos Swiss, machos com idade entre 7 a 12 semanas fornecidos pela Indústria Química do Estado de Goiás (IQUEGO). Os animais foram mantidos agrupados ao acaso em gaiolas plásticas, em sala climatizada sob temperatura constante de $26 \pm 2{ }^{\circ} \mathrm{C}$, com ciclo claro-escuro de $12 \mathrm{~h}$. O regime alimentar foi o clássico, com ração comercial padrão e água fornecida ad libitum. Para a realização 
do ensaio de mutagenecidade os animais foram divididos em grupos controles (controle negativo, controle do veículo e controle positivo) e expostos ao extrato da planta por via oral, em diferentes doses $(10,25$ ou $50 \mathrm{mg} / \mathrm{kg} / \mathrm{dia})(\mathrm{n}=5 /$ grupo). Os ensaios em animais foram realizados de acordo com os Princípios Éticos de Experimentação Animal do Conselho Brasileiro de Experimentação Animal.

\section{Ensaios in vitro}

Para a realização dos ensaios de citotoxicidade in vitro sobre as células da medula óssea, 5 animais normais foram sacrificados por deslocamento cervical e a medulas ósseas foram assepticamente coletadas em um tubo de ensaio com o auxílio de uma seringa contendo $1 \mathrm{~mL}$ de solução fisiológica estéril. Em seguida, a suspensão celular foi centrifugada por 5 minutos a $2000 \mathrm{rpm}$ e o sobrenadante descartado. O botão celular foi ressuspenso em $2 \mathrm{~mL}$ de meio de cultura RPMI (Sigma ${ }^{\circledR}$ ) suplementado com $15 \%$ de soro bovino fetal inativado (Nutricell ${ }^{\circledR}$ ) e antibióticos $100 \mathrm{UI} / \mathrm{mL}$ (estreptomicina e penicilina Sigma ${ }^{\circledR}$ ). Em seguida, realizou-se a contagem das células viáveis em azul de tripano para o ajuste da concentração em $2 \times 10^{6}$ células/ $\mathrm{mL}$ para a posterior realização dos ensaios de citotoxicidade. Esta concentração celular foi adotada após estudo prévio utilizando diferentesconcentrações de células.

\section{Avaliação de citotoxicidade pelo método de redução do MTT}

O princípio deste método consiste na absorção do sal MTT \{brometo de [3-(4,5-dimetiltiazol-2-i1)-2,5difeniltetrazólio]\} (Sigma $\left.{ }^{\circledR}\right)$ pelas células, sendo reduzido no interior da mitocôndria a um produto chamado formazana. Este produto, acumulado dentro da célula, é extraído através da adição de um solvente apropriado (Mosmann, 1983).

A suspensão celular de animais normais na concentração de $2 \times 10^{6}$ células $/ \mathrm{mL}$ foi distribuída em uma placa de 96 poços, $90 \mu \mathrm{L}$ por poço, e incubadas a $37^{\circ} \mathrm{C}$ em incubadora a $5 \%$ de $\mathrm{CO}_{2}$ juntamente com mais $10 \mu \mathrm{L}$ da amostra teste. Neste estudo foram utilizadas diferentes concentrações $(40 ; 20 ; 10 ; 5 ; 2,5 ; 1,25 ; 0,625 ; 0,312 \mathrm{mg} / \mathrm{mL})$ do EESU. O experimento foi incubado por 12, 24 ou $48 \mathrm{~h}$, em triplicata. Após o período de incubação adicionou-se mais $10 \mu \mathrm{L}$ do corante MTT $\left(5 \mathrm{mg} / \mathrm{mL}\right.$, Sigma $\left.{ }^{\circledR}\right)$ e as células foram novamente incubadas por mais $4 \mathrm{~h}$. Em seguida, o meio foi retirado cuidadosamente e adicionaram-se $100 \mu \mathrm{L}$ de dimetilsulfóxido $\left(\mathrm{DMSO}\right.$, Sigma $^{\circledR}$ ) para solubilização dos cristais de formazana. As placas foram agitadas durante 5 minutos e a absorvância correspondente a cada amostra foi medida no leitor de ELISA (Enzyme-Linked
Immunosorbent Assay) a $560 \mathrm{~nm}$. A absorvância obtida das células controle, não-tratadas, foi considerada como $100 \%$ de viabilidade celular (Mosmann, 1983).

\section{Avaliação de citotoxicidade pelo método de exclusão} do azul de tripano

Este método avalia a integridade da membrana celular. A suspensão celular de animais normais na concentração de $2 \times 10^{6}$ células $/ \mathrm{mL}$ foi distribuída em uma placa de 96 poços, $90 \mu \mathrm{L}$ por poço, e incubadas a $37^{\circ} \mathrm{C} \mathrm{em}$ incubadora a $5 \%$ de $\mathrm{CO}_{2}$ juntamente com mais $10 \mu \mathrm{L}$ da amostra teste. Neste estudo foram utilizadas diferentes concentrações $(40 ; 20 ; 10 ; 5 ; 2,5 ; 1,25 ; 0,625 ; 0,312 \mathrm{mg} / \mathrm{mL})$ do EESU. O experimento foi incubado por 12, 24 ou $48 \mathrm{~h}$, em triplicata. Após estes períodos de incubação, uma alíquota de $20 \mu \mathrm{L}$ da suspensão de células foi retirada e diluída em azul de tripano $\left(0,04 \%\right.$, Sigma $\left.{ }^{\circledR}\right)$. As células foram observadas por suas alterações morfológicas e contadas em câmara de Neubauer. As células viáveis, que excluíram o corante, possuíam aspecto translúcido e as células mortas apresentavam coloração arroxeada.

\section{Ensaios in vivo}

\section{Avaliação do potencial mutagênico do extrato de Synadenium umbellatum}

Para a avaliação do potencial mutagênico do extrato etanólico do Synadenium umbellatum os animais foram expostos a diferentes doses $(10,25$ e $50 \mathrm{mg} / \mathrm{kg})$ do EESU, dose única, via oral. Vinte e quatro horas após a exposição, os animais foram sacrificados por deslocamento cervical e a medula foi colhida com o auxílio de uma seringa. O grupo controle recebeu somente o veículo da droga (10:1 de solução fisiológica estéril/Tween 80).

Os grupos experimentais ficaram assim distribuídos (5 animais/grupo): Grupo I: controle negativo (não recebeu tratamento); Grupo II: controle do veículo (recebeu somente o veículo da droga); Grupo III: controle positivo (ciclofosfamida $200 \mathrm{mg} / \mathrm{kg}$ ); Grupo IV: EESU $10 \mathrm{mg} / \mathrm{kg}$; Grupo V: EESU 25 mg/kg e Grupo VI: EESU 50 mg/kg.

\section{Preparo das lâminas para pesquisa de micronúcleo}

Após a coleta da medula óssea, as células foram centrifugadas por 5 minutos a $2000 \mathrm{rpm}$ por 2 vezes descartando-se o sobrenadante. Da suspensão resultante, uma pequena gota foi retirada e colocada na extremidade da lâmina para a realização do esfregaço. Após a secagem do esfregaço, as lâminas foram coradas com Leishman e secas à temperatura ambiente. Em seguida, aplicou-se uma gota pequena de Bálsamo do Canadá no centro da lâmina para a fixação da lamínula. As lâminas foram analisadas 
em teste cego, usando aumento de 1.000x. Foram analisados 1.000 eritrócitos por lâmina, em triplicata.

\section{Análise estatística}

Os dados foram avaliados utilizando o método estatístico de Análise de Variância (ANOVA) e o teste a posteriori de Tukey. Para todos os grupos considerou-se estatisticamente significativos quando $P<0,05$.

\section{RESULTADO E DISCUSSÃO}

No presente estudo avaliamos o potencial citotóxico, in vitro, e mutagênico, in vivo, do extrato bruto do Synadenium umbellatum sobre as células da medula óssea de camundongos. Os resultados aqui apresentados demonstraram que o EESU induziu citotoxicidade e danos ao DNA de células da medula óssea de camundongos.

O potencial citotóxico do EESU foi investigado pelos métodos de exclusão do azul de tripano e redução do tetrazólio MTT (Figuras 1 e 2). Utilizando o método de exclusão do azul de tripano investigamos o efeito do EESU, em diferentes concentrações, $(0,312-40 \mathrm{mg} / \mathrm{mL})$ sobre a integridade da membrana de células da medula óssea em cultura por 12, 24 ou $48 \mathrm{~h}$. Neste ensaio, os resultados demonstraram efeito citotóxico concentração-dependente e tempo-dependente, em todos os intervalos investigados. Os valores da concentração inibitória $50 \%\left(\mathrm{CI}_{50}\right)$, obtido nas curvas de concentração-resposta, ficaram por volta de 7,9; 5,2 e 3,6 mg/mL nos intervalos de 12,24 e $48 \mathrm{~h}$, respectivamente.

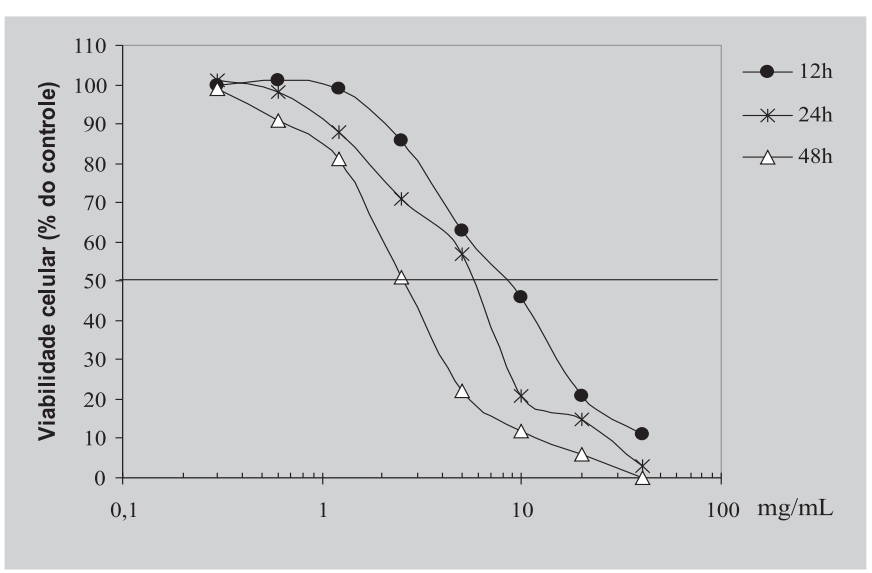

FIGURA 1- Viabilidade celular de células da medula óssea de animais normais após 12, 24 ou 48 h de exposição a diferentes concentrações do Synadenium umbellatum $(0,312$ $40 \mathrm{mg} / \mathrm{mL}$ ) pelo método de azul de tripano. Cada ponto representa a média e desvio padrão da triplicata. A barra horizontal representa a concentração inibitória $50 \%\left(\mathrm{CI}_{50}\right)$.

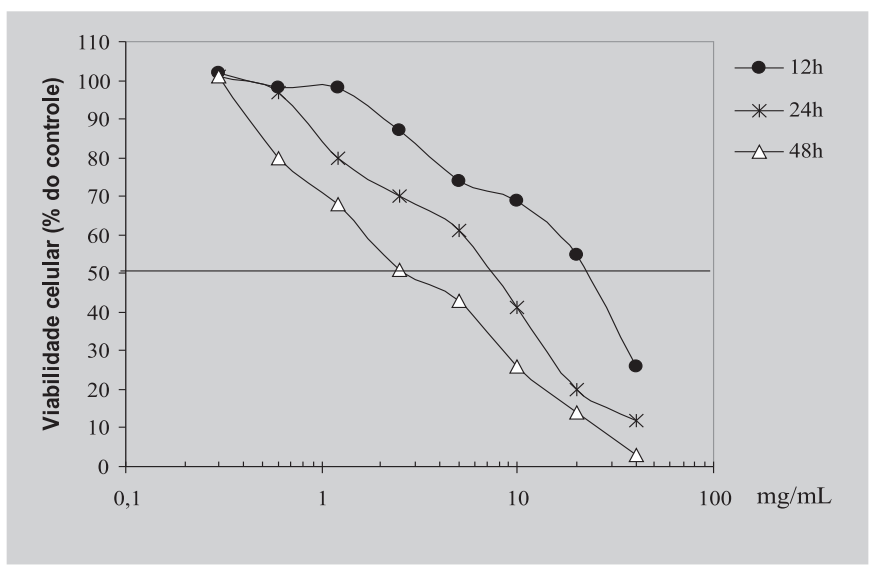

FIGURA 2 - Viabilidade celular de células da medula óssea de animais normais após 12, 24 ou 48 h de exposição a diferentes concentrações do Synadenium umbellatum $(0,312-40 \mathrm{mg} / \mathrm{mL})$ pelo método de redução do tetrazólio MTT. Cada ponto representa a média e desvio padrão da triplicata. A barra horizontal representa a concentração inibitória $50 \%\left(\mathrm{CI}_{50}\right)$.

No ensaio de redução do tetrazólio MTT, semelhante aos resultados encontrados no ensaio anterior, a presença do extrato, nas diferentes concentrações estudadas $(0,312-40$ $\mathrm{mg} / \mathrm{mL}$ ), reduziu a viabilidade das células da medula óssea em cultura em todos os intervalos investigados, quando comparado ao controle (Figura 2), de forma concentração- dependente. Os valores de $\mathrm{CI}_{50}$, obtidos da curva de concentração-resposta, ficaram por volta 18,0; 7,0 e 3,6 mg/mL nos intervalos de 12, 24 e $48 \mathrm{~h}$, respectivamente. Uma vez que os métodos empregados nesta avaliação de citotoxicidade possuem objetivos distintos, diferenças na $\mathrm{CI}_{50}$ são esperadas. O teste de redução do MTT avalia a capacidade da enzima succinato desidrogenase de reduzir o substrato MTT a cristais de formazana na mitocôndria da célula (Mosmann, 1983). Por outro lado, o teste de exclusão do corante azul de tripano estuda a permeabilidade da membrana plasmática (Barile, 1994). Portanto, mesmo a membrana sendo lisada por um agente citotóxico, organelas citoplasmáticas podem, ainda, manter sua atividade fisiológica. Vale ressaltar que a atividade citotóxica aqui demonstrada corrobora os estudos da literatura, os quais reportam atividades citotóxicas de euforbiáceas. Nestes estudos, o mecanismo de ação da citotoxicidade está associado à capacidade destas plantas de induzir apoptose celular. Block et al. (2005) demonstraram que triterpenos isolados da Euforbiaceae Croton zambesicus induzem morte celular programada em células leucêmicas promielocíticas humanas por meio da ativação da protease caspase-3. Uthaisang et al., 2004, observaram que o peptídeo VR-3848, isolado de uma Euforbiaceae, além de 
ativar proteases, induz modulação negativa da proteína antiapoptótica $\mathrm{Bcl}-2$. Recentemente, um estudo demonstrou que a Euphorbia cheiradenia induz fragmentação de DNA e apoptose em células leucêmicas (Amirghofran et al., 2006). Ademais, estudos preliminares realizados pelo nosso grupo apontam para atividade citotóxica do EESU sobre as células leucêmicas K-562.

Está bem estabelecido na literatura que a exposição terapêutica a xenobióticos pode resultar em ligação covalente com o DNA e danos genéticos, o que poderia ser um evento inicial no processo de carcinogênese química (Ribeiro et al., 2006). Agentes antineoplásicos como a ciclofosfamida apresentam propriedades alquilantes, complexando-se com o DNA, de forma indiscriminanda, entre células normais e cancerosas. Desta forma, paradoxalmente, inúmeros relatos na literatura apontam para o potencial carcinogênico da ciclofosfamida. Kijima et al. (2000) relataram casos de aparecimento de carcinoma secundário transicional em pacientes que receberam altas doses de ciclofosfamida por períodos longos.

Os resultados da investigação do potencial mutagênico do EESU estão representados nas Figuras 3 e 4 . Como já esperávamos, nossos resultados corroboram os dados da literatura demonstrando o efeito mutagênico da ciclofosfamida, expresso pelo aumento significativo da freqüência de micronúcleos, quando comparado ao grupo controle sem exposição ( $P<0,05$; ANOVA, teste Tukey). Da mesma forma, a exposição dos camundongos às diferentes doses $(10 \mathrm{mg} / \mathrm{kg}, 20$ $\mathrm{mg} / \mathrm{kg}$ ou $50 \mathrm{mg} / \mathrm{kg} /$ dia) do extrato etanólico do Synadenium umbellatum também aumentou significativamente a freqüência de micronúcleo $(P<0,05$; ANOVA, teste Tukey), de forma dose-dependente, quando comparado ao grupo controle. Além disso, nos grupos de animais tratados com as maiores doses, $20 \mathrm{mg} / \mathrm{kg}$ e $50 \mathrm{mg} / \mathrm{kg}$, observaram-se um aumento no número de micronúcleo de $110 \%$ e $121 \%$, respectivamente, em comparação ao grupo controle que somente recebeu o solvente da droga. Embora a exposição dos animais ao EESU na dose de $10 \mathrm{mg} / \mathrm{kg}$ tenha aumentado a freqüência de micronúcleos em $39,6 \%$, em relação ao grupo controle, nenhuma diferença estatística significativa foi observada neste grupo.

\section{CONCLUSÃO}

O estudo do equilíbrio entre efeitos terapêuticos e efeitos adversos de um novo fármaco, mesmo nos estágios iniciais da pesquisa, é de crucial importância quando se vislumbra a sua aplicabilidade clínica. Diante do exposto, os dados aqui apresentados indicam que o EESU possui potencial mutagênico e citotóxico, dose-dependente, sobre as células da medula óssea de camundongos. Estudos sobre o potencial antineoplásico do extrato bruto do EESU

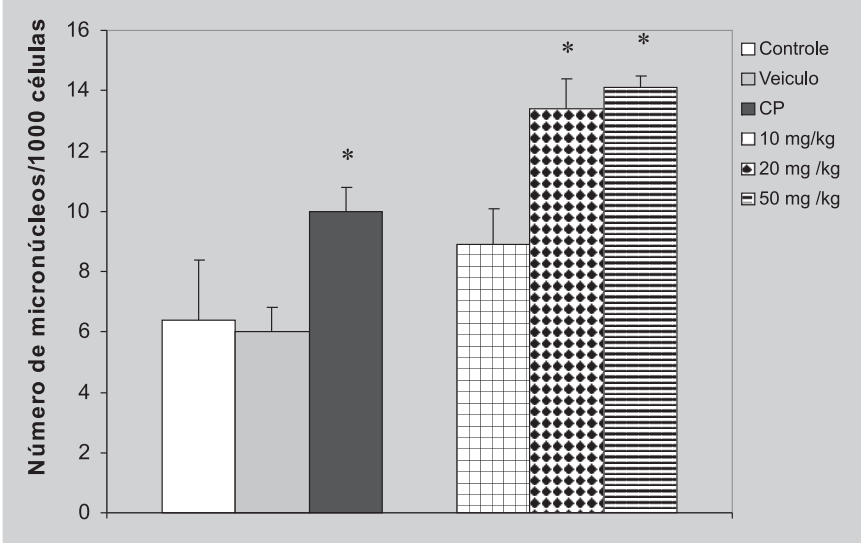

FIGURA 3 - Avaliação da freqüência de micronúcleos em eritrócitos (1000/lâmina) de animais ( $\mathrm{n}=5 /$ grupo) expostos a uma única dose de diferentes concentrações do extrato alcoólico do Synadenium umbellatum $(10,20$ ou $50 \mathrm{mg} / \mathrm{kg} /$ dia; v.o.). O grupo controle positivo recebeu uma única dose de ciclofosfamida (CP) $(200 \mathrm{mg} / \mathrm{kg} /$ dia $)$. Os animais foram sacrificados $24 \mathrm{~h}$ após a exposição para a avaliação da incidência de micronúcleos. O grupo controle não recebeu tratamento e o grupo veículo recebeu somente o solvente da droga. Os valores acima representam a média e o desvio padrão de cada respectivo grupo. ANOVA, Teste de Tukey. * $P<0,05$ em relação ao grupo controle.

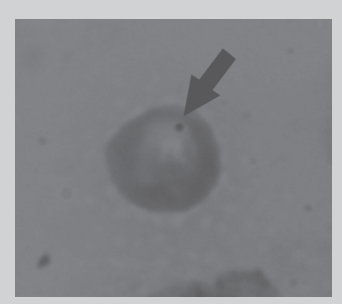

FIGURA 4 - Fotomicrografia indicando a formação de micronúcleo em eritrócito de camundongo exposto ao extrato etanólico do Synadenium umbellatum $(50 \mathrm{mg} / \mathrm{kg} /$ dia), via oral, em dose única.

estão em andamento pelo nosso grupo e deverão contemplar a avaliação mais ampla dos efeitos desta planta sobre a atividade funcional das células da medula óssea.

\section{ABSTRACT}

\section{Synadenium umbellatum: cytotoxicity and DNA damage to bone marrow cells from mice}

In the present study we investigated, in vitro and in vivo, the cytotoxic and mutagenic potential of the Synadenium umbellatum ethanolic extract (SUEE) on the bone marrow 
cells of mice. In vitro cytotoxicity was assayed incubating bone marrow cells with different concentrations (40-0.312 $\mathrm{mg} / \mathrm{mL}$ ) of SUEE for 12, 24 or $48 \mathrm{~h}$ using the MTT tetrazolium reduction test and the trypan blue exclusion test. The micronuclei assay was performed to determine mutagenic effects of mice orally exposed to different doses of SUEE $(10,25 \mathrm{or} 50 \mathrm{mg} / \mathrm{kg} /$ day) in $24 \mathrm{~h}$. Our results demonstrated that SUEE has, in a dose-dependent manner, potential cytotoxic and mutagenic effects on the bone marrow cells of mice. Further studies are needed to expand the knowledge of the toxicologicall pharmacological potential of the SUEE.

UNITERMS: Synadenium umbellatum./cytotoxicity. Micronuclei. Bone marrow/experimental study. DNA/ damage.

\section{AGRADECIMENTOS}

Este trabalho foi realizado com o apoio financeiro do Conselho Nacional de Desenvolvimento Científico e Tecnológico (CNPq).

\section{REFERÊNCIAS BIBLIOGRÁFICAS}

ABO, K.A.: Screening extracts of Euphorbia garuana N.E.Br. for in vitro cytotoxicity. Afr. J. Med. Med. Sci., v.17, p.227-230, 1988.

AMIRGHOFRAN, Z.; BAHMANI, M.; AZADMEHR, A.; JAVIDNIA, K. Induction of apoptosis in leukemia cell lines by Linum persicum and Euphorbia cheiradenia. J. Cancer Res. Clin. Oncol., v.132, p.427-432, 2006.

AZEVEDO, L.; GOMES, J.C.; STRINGHETA, P.C.; GONTIJO, A.M., PADOVANI, C.R.; RIBEIRO, L.R.; SALVADORI, D.M.F. Black bean (Phaseolus vulgaris $L$.) as a protective agent against DNA damage in mice. Food Chem. Toxicol., v.41, p.1671-1671, 2003.

BARILE, F.A. In vitro cytotoxicology. New York: CRC Press, 1994. 96p.

BLOCK, S.; GERKENS, P.; PEULEN, O.; JOLOIS, O.; MINGEOT-LECLERCQ, M.P; DE PAUW-GILLET, M.C.; QUETIN-LECLERCQ, J. Induction of apoptosis in human promyelocytic leukemia cells by a natural trachylobane diterpene. Anticancer Res., v.25, p.363-368, 2005.
D’ÁVILA, E.D.P.; CUNHA, L.C. Intoxicações por plantas tóxicas: casos notificados ao Centro de Informação Toxicológica de Goiás no período de 1986 a 2000. Goiânia: Universidade Federal de Goiás, 2001. 57p. [Monografia de Especialização em Toxicologia].

DELDAR, A.; LEWIS, H.; BLOOM, J.; WEISS, L. Reproducible cloning assays for in vitro growth of canine hematopoietic progenitor cells and their potential applications in investigative hematotoxicity. Am. J. Vet. Res., v.49, p.1393-1340, 1988.

DIODOVICH, C.; BIANCHI, M.G.; BOWE, G.; ACQUATI, TARAMELLI, R.; PARENT-MASSIN， D.; GRIBALDO, L. Response of human cord blood cells to styrene exposure: evaluation of its effects on apoptosis and gene expression by genomic technology. Toxicology, v.5, p.45-57, 2004.

FURSTENBERBER, G., HECKER, E. On the active principles of the Euphorbiaceae: XII. Highly unsaturated irritant diterpene esters from Euphorbia tirucalli originating from Madagascar. J. Nat. Prod., v.49, p.386397, 1986

GRIBALDO, L.; ALISON, M.; ANDREWS, P.W.; BREMER, S.; DONOVAN, P.J.; KNAAN-SHANZER, S.; MERTELSMANN, R.; SPIELMANN, H.; TESTA, N.G.; TRIFFITT, J.T.; ZIPORI, D.; DE WYNTER, E. Meeting summary: European Workshop on Stem Cells, European Centre for the Validation of Biomedical Testing Methods, Institute for Health and Consumer Protection, Joint Research Centre, Ispra, Italy, November 21-23, 2001. Exp. Hematol., v.30, p. 628-633, 2002.

GRIBALDO, L.; MALERBA, I.; COLLOTTA, A.; CASATI, S.; PESSINA, A. Inhibition of CFU-E/BFU-E by 3'-azido- 3'-deoxythymidine, chlorpropamide, and protoporphirin IX zinc (II): a comparison between direct exposure of progenitor cells and long-term exposure of bone marrow cultures. Toxicol. Sci., v.58, p.96-101, 2000.

HUBERT, A.; De-THÉ, G. Dietary behavior, way of life, and nasopharyngeal cancer. Bull. Cancer, v.5, p.476-482, 1982.

IMAI, S.; SIGIURA, M.; MIZUNO, F.; OHIGASHI, H.; KOSHIMIZU, K.; CHIBA, S.; OSATO, T. African Burkitt's lymphoma: a plant, Euphorbia tirucalli, reduces Epstein-Barr virus-specific cellular immunity. Anticancer Res., v.14, p.933-936, 2002. 
JÄGER, A.K.; HUTCHINGS, A.; VAN STADEN, J. Screening of Zulu medicinal plants for prostaglandinsynthesis inhibitors. J. Ethnopharmacol., v.52, p.95-100, 1996.

JOLY, A.B. Botânica: introdução a taxonomia vegetal. 4.ed. São Paulo: Editora Nacional, 1977. 87p.

KIJIMA, T.; MASUDA, H.; SUZUKI, M.; OKADA Y., YANO, M.; HYOCHI, N.; FUJI, Y.; KAWAKAMI, S.; HAYASHI, T.; KOBAYASHI, T.; KIHARA, K. Cyclophosphamide-induced bladder cancer: three case reports. Hinyokika Kiyo, v.49, p.483-486, 2003.

KUPCHAN, S.M.; UCHIDA, I.; BRANFMAN, A.R.; DAILEY, R.G.; FEI, B.Y.Antileukemic principles isolated from euphorbiaceae plants. Science, v.191, p.571-572, 1976.

MACNEIL, A.; SUMBA, O.P.; LUTZKE, M.L.; MOORMANN, V.; ROCHFORD, R. Activation of the Epstein-Barr virus lytic cycle by the latex of the plant Euphorbia tirucalli. Br. J. Cancer, v.19, p.1566-1569, 2003.

MATEUCA, R.; LOMBAERT, N.; AKA, P.V.; DECORDIER, I., KIRSCH-VOLDERS, M. Chromosomal changes: induction, detection methods and applicability in human biomonitoring. Biochimie, v.88, p.515-1531, 2006.

MOSMANN, T. Rapid colorimetric assay for cellular growth and survival. J. Immunol. Methods, v.65, p.55-63, 1983.

NEGRO, G.D.; BONATO, M.; GRIBALDO, L. In vitro bone marrow granulocyte-macrophage progenitor cultures in the assessment of hematotoxic potential of the new drugs. Cell Biol. Toxicol., v.17, p.95-105, 2001 .

ORTÊNCIO, W.B. Medicina popular do Centro-Oeste. 2.ed. Brasília: Thesaurus, 1997. 59p.

PARCHMENT, R.E. Alternative testing systems for evaluating non-carcinogenic, hematologic toxicity. Environ. Health Perspect., v.106, supp1.2, p.541-557, 1998.

PARENT-MASSIN, D.; THOUVENOT, D. In vitro study of pesticide hematotoxicity in human and rat progenitors. $J$. Pharmacol. Toxicol. Methods, v.30, p.203-207, 1993.
PESSINA, A.; ALBELLA, B.; BAYO, M.; BUEREN, J.; BRANTOM, P.; CASATI, S.; CROERA, C.; GAGLIARDI, G.; FOTI, P.; PARCHMENT, R.; PARENT-MASSIN, D.; SCHOETERS, G.; SIBIRIL, Y.; VAN DEN HEUVEL, R.; GRIBALDO, L. Application of the CFU-GM assay to predict acute drug-induced neutropenia: an international blind trial to validate a prediction model for the maximum tolerated dose (MTD) of myelosuppressive xenobiotics. Toxicol. Sci., v.75, p.355-367, 2003.

PESSINA, A.; ALBELLA, B.; BUEREN, J.; BRANTOM, P.; CASATI, S.; GRIBALDO, L.; CROERA, C.; GAGLIARDI, G.; FOTI, P.; PARCHMENT, R.; PARENT-MASSIN, D.; SIBIRIL, Y.; VAN DEN HEUVEL, R. Prevalidation of a model for predicting acute neutropenia by colony forming unit granulocyte/ macrophage (CFU-GM) assay. Toxicol. In Vitro, v.15, p.729-740, 2001.

QUER, P.F. Plantas medicinales: el dioscorides renovado. Barcelona: Editorial Labor, 1962. 1033p.

REZENDE, O.S.J.; PALHAES, L.B.; CUNHA, L.C. Intoxicações por plantas tóxicas notificadas no CIT Centro de Informação Toxicológica de Goiás no periodo de 2001 a 2005. Goiânia: Universidade Federal de Goiás, 2006. 72p. [Monografia de Especialização].

RIBEIRO, D.A.; LIMA P. L.; MARQUES M.E.; SALVADORI, D.M. Lack of DNA damage induced by fluoride on mouse lymphoma and human fibroblast cells by single cell gel (comet) assay. Braz. Dent. J., v.17, p.9194, 2006.

SCHENKEL E.P.; GOSMANN G.; PETROVICK P.R. Produtos de origem vegetal e o desenvolvimento de medicamentos. In: SIMÕES, C.M.O.; SCHENKEL, E.P.; GOSMANN, G.; MELLO, G.C.P.; MENTZ, L.A.; PETROVICK, P.R. eds. Farmacognosia: da planta ao medicamento. Florianópolis: Editora da Universidade Federal de Santa Catarina, 1999. p.86.

SCHRODER, G.; ROHMER, M.; BECKT, J.P.; ANTON, R. 7-oxo-, $7 \alpha$-hydroxy and $7 \beta$-hydroxysterols from Euphorbia fischeriana. Phytochemistry, v.19, p.22132245, 1980. 
UTHAISANG $\quad$ W.; $\quad$ REUTRAKUL $\quad$ V.; $\quad$ VAN DEN BOSCH, C.; GRIFFIN, B. E.; KAZEMBE, P.; KRACHANGCHAENG C.; WILAIRAT P.; FADEEL B. VR-3848, a novel peptide derived from Euphobiaceae, induces mitochondria-dependent apoptosis in human leukemia cells. Cancer Lett., v.28, p.171-178, 2004.

VALADARES, M.C.; CARRUCHA, S.G.; ACCORSI W.; QUEIROZ, M.L. Euphorbia tirucalli L. modulates myelopoiesis and enhances the resistance of tumourbearing mice. Int. Immunopharmacol., v.6, p.294-299, 2005.

DZIWENI, C.; KADZAMIRA, L. Are plant factors a missing link in the evolution of endemic Burkitt's lymphoma? Br. J. Cancer, v.6, p.1232-1235, 1993.

YAMAGUCHI, F.; FURUHAMA, K.; MIYAMOTO, M.; SAGARA-ISHIJIMA, N.; TAKAYAMA, S. Application of hematopoietic progenitor assays for the estimation of hematotoxicity in rats. J. Pharmacol. Toxicol. Methods, v.31, p.71-77, 1994.

Recebido para publicação em 24 de outubro de 2006. Aceito para publicação em 27 de novembro de 2007. 